16 Tropelías. Revista de Teoría de la Literatura y Literatura Comparada, 18 (2012)

Juan Carlos Rodríguez

\title{
SUBJETIVIDAD Y SUBJETIVACIÓN EN LA CULTURA DE HOY (NOTAS SOBRE FOUCAULT Y HEIDEGGER Y OTRAS CUESTIONES ANEXAS)
}

\author{
Juan Carlos RODRÍGUEZ
}

Universidad de Granada

\section{Convirtiéndonos en Nadie}

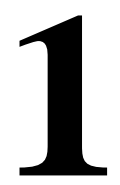

Es evidente que la superpolitización de los años 60-70 fue un globo hinchado hasta reventar para conseguir que se impusiera así el yo libre. A eso se le acabó llamando Posmodernidad. En cuanto el yo libre triunfó nos dimos cuenta de que en la cama no estaba la abuelita sino el lobo, que nos deglutía de inmediato: no es sólo que tuviera los dientes grandes, es que nos tragó a todos de un bocado. En cada eructo, el viejo lobo capitalista (con más de quinientos años y astuto y ávido como él solo) nos dejaba seguir diciendo: yo soy libre, nacimos libres. Y luego cerraba la boca y en aquel psiquiátrico global se comenzó a oír el susurro: soy nadie.

Claro que con ese nombre -Nadie- se salvó Ulises (aunque antes tuviera que cegar a Polifemo y aunque Góngora resucitara luego al Cíclope con su ojo omniabarcador). Y claro que Alicia vio correr a Nadie (y el rey se asombró de la buena vista de Alicia: ;había visto a Nadie!); y claro que nosotros le habíamos visto muchas veces "las orejas al lobo" (pero estaba en el maravilloso technicolor de Disney y todo el mundo quería que "viniera el lobo", la buena abuelita). Ahora que estamos en su esófago, ¿qué decir?, ¿qué hacer?

Obviamente este cuento no se lo ha inventado Perrault ni los Grimm (ni por supuesto yo: ¡ojalá!).

Este cuento ha sido -y sobre todo es- nuestra vida mísera, de aquí y ahora, nuestra lírica subjetiva y nuestra poesía no-lírica u objetiva. 
De modo que intentaré rastrear algunas huellas de cómo se planteó (en el nivel ideológico al menos) ese paso desde el yo-libre al "yo soy-nadie" (o yo-nada, que también vale). Problemas de subjetividad o subjetivación, como digo.

2. En una de las últimas notas de mi reciente libro Para una lectura de Heidegger (Rodríguez, 2011) necesité precisar que no podía desarrollar allí en extenso la influencia de Heidegger en el Psicoanálisis lacaniano y en los Estudios Culturales de hoy. De manera que intentaré reincidir en la misma puntualización ahora, sólo que desarrollando determinados hitos que me parecen fundamentales al respecto. Con una distinción clara: Heidegger, lógicamente, jamás se preocupó por el trasfondo capitalista del nazismo; y Foucault (a pesar de su breve paréntesis izquierdista a finales de los sesenta) sólo habló del Poder y de las tecnologías de o sobre el yo (veremos enseguida su vertiente neoliberal última, si bien jamás intuyó el nido de víboras que allí se engendraba). Pero lo que es quizá comprensible en ambos, resulta incomprensible en el Constructivismo cultural de hoy: no sólo por el azote arrasador del capitalismo financiero, sino por las nuevas formas de subjetivación que ese mismo capitalismo neoliberal nos ha impuesto: el cálculo y el beneficio como única capilarización de vida interna o intersubjetiva (normas afectivas o de cualquier tipo).

Pero vayamos al grano.

Evidentemente los planteamientos de Heidegger, antes y después de la Carta sobre el humanismo de 1946-1949 han dado lugar a una serie de malentendidos y reescrituras más o menos tergiversadoras, cuyos efectos asombran. Veamos algunos ejemplos significativos.

En primer lugar, decimos, las reescrituras heideggerianas de Foucault (puesto que Foucault hoy sigue siendo clave en el constructivismo de los Estudios culturales y de los Estudios de género en los USA y por tanto en Europa). Señalaremos algunos síntomas a través de las diversas formas de subjetivación (o de manifestaciones discursivas) que la subjetividad de Foucault nos ha ido ofreciendo. Pues lo realmente sintomático es esto: Foucault siempre se movió dentro del planteamiento sujeto/sistema (la dicotomía clave de la Metafísica para Heidegger) y siempre inclinándose hacia el sujeto hasta su desbordamiento final en la apología del neoliberalismo y del yo libre. Su supuesto "antihumanismo" de la segunda mitad de los sesenta (hasta principios de los setenta inclusive), sólo implicaba un rechazo de la idea del Hombre de aquellos Ilustrados que nunca habrían conectado a ese Hombre con las tecnologías del yo de las sociedades disciplinarias del XVII y que nunca lo habrían conectado con la relación poder/saber del mundo burgués (la ley, el orden, el juez y el médico, la familia, el 
encierro, el Panóptico, el castigo y la autoridad, y sobre todo el sexo). O sea, todos los dispositivos del Poder (y sus alternativas: la resistencia y las diversas formas de subjetivación). En las sociedades de control actuales se habría establecido claramente la imagen de la biopolítica (que ya había aparecido en Historia de la locura). La biopolítica sería para Foucault una alternativa a la economía política -y por supuesto al marxismo- en tanto que noción concebida como mezcla de lo que en el mundo griego sería zoé (o vida natural, doméstica) y bios (o sea, intervención en el ágora clásica). Cuando en el XVIII esa mezcla de zoé y bios se convirtió en Economía política (lo cual supondría para Foucault una tergiversación) se habría descubierto al menos lo que Foucault iba a llamar la aparición de la vida en la historia, o sea, la aludida biopolítica. El control de las vidas (en el sentido fluido y flexible de hoy: lo "líquido" de G. Agamben) permitiría por fin la creación de un yo libre asumiendo su propia vida y sus propios riesgos; aunque el riesgo implique, para Foucault, también una seguridad o gobernabilidad, en el propio autocontrol y en las relaciones con los otros (lógicamente el éxito de tales planteamientos "libres" de Foucault en los USA iba a ser incontrovertido).

Esto en primer lugar. Pero tal especie de anarquismo vital controlado implicaba además no creer en el "esencialismo" del yo social. No creer, pues, en la naturaleza esencial de las imágenes de los normales y los anormales, de los homosexuales y los heterosexuales, la no esencialidad de las tecnologías del yo (o sobre el yo). En 1975 lo señalaba Foucault en una de sus entrevistas con R. P. Droit: por ser homosexual, ¿sería él diferente, sería anormal o quizá incluso un enfermo? De ahí su decisión de no ser psicólogo y de ahí sus ataques a todas las ciencias humanas, que no harían más que naturalizar o esencializar los dispositivos del poder ${ }^{1}$. Por supuesto que Poder (y Fuerzas), esos términos imprecisamente arrancados de Nietzsche (pero que se colaban en todos los intersticios), le servían a Foucault para atacar no sólo al marxismo (que se suponía como concentración de poder) sino al psicoanálisis de Freud/Lacan por supuesta esencialización de la norma heterosexual, etc.

Pero vayamos más despacio. Obsesionado por salir de la originaria Fenomenología psico-terapéutica en la que se formó (el existencialismo de L. Binswanger sobre todo) y tras su muy coyuntural relación Nietzsche/comunismo, Foucault se convierte en Foucault en los años sesenta -se sabe- a través de sus tres libros "arqueológicos" más famosos: una arqueología de la mirada médica (o sea, El nacimiento de la clínica, 1963); una arqueología de las ciencias humanas (o sea, Las

\footnotetext{
${ }^{1}$ Cfr. Moreno Pestaña (2006 y 2010). Debería señalar de antemano mi profundo respeto por la obra de Foucault. En este trabajo señalo las líneas en las que "disiento", sobre todo por su influencia en los Estudios culturales y por su imagen de la subjetividad libre, una cuestión ésta en la que -insisto- hoy cree prácticamente todo el mundo.
} 
palabras y las cosas, 1966) y la Historia de la locura en la época clásica, 1972 (más, un poco antes, La arqueología del saber, 1969). Sintomáticamente Foucault rompe con la "angustia existencial" a través de tres líneas: el simbolismo neokantiano de la cultura en Cassirer (ese neosimbolismo también lo recogerá Lacan); la óptica o la mirada (como igualmente hará Lacan) de Merleau-Ponty, de quien Foucault toma el término arqueología, como "capa cultural" vs. el término geología como "capa natural”; y la imagen del "ser-para-la-muerte" del primer Heidegger (aunque algunos lacanianos nieguen esto, lo hacen por su cuenta). De todos modos (y como se ve), una curiosa manera de salir de la Fenomenología existencial "a la francesa" por sus líneas de fuga más espaciales y menos esencialistas. De ahí el famoso comienzo de El nacimiento de la clínica (Foucault, 1966): «Este libro trata del espacio, del lenguaje y de la muerte; trata de la mirada».

El espacio y la mirada son de Merleau-Ponty; el espacio y la muerte son de Heidegger; pero ¿de quién es el lenguaje? Por supuesto ahí hay algo también de reescritura de Heidegger, pero sobre todo del panlingüisticismo de la época (es el descubrimiento de Saussure, de los Formalistas rusos, de R. Jakobson y de todo el lingüisticismo analítico/formal vienés-berlinés trasplantado al mundo angloamericano ${ }^{2}$ ). Pero en especial, en el caso de Foucault, se trataba del lingüisticismo literario/ izquierdista de la revista Tel Quel de Philippe Sollers, Julia Kristeva, etc., con RobbeGrillet y Raymond Roussel al fondo, a la vez que de la más seria ${ }^{3}$ Critique, con Bataille, Klossowski, Blanchot, etc., con sus nociones clave de límite, transgresión y lenguaje -por supuesto. Lo curioso es que la revista Critique provenía obviamente de esos discípulos a los que Kojève, aquel oscuro funcionario del Ministerio francés de Agricultura, había fascinado con sus cursos sobre la Fenomenología del Espíritu de Hegel en los años treinta (cursos a los que también asistieron Paul de Man, Lacan o R. Queneau, que recopiló y publicó los cursos, etc.). El Hegel de Kojève no era el Hegel al que también intentó acercarse el joven Foucault, sino que era el de la "tragedia" del Espíritu Objetivo que se extraviaba en el mundo, que no se auto-reconocía jamás como Espíritu Absoluto y que, por tanto, se interiorizaba y se condenaba al fracaso de cualquier vida y cualquier escritura: en el fondo, tanto en Tel Quel como en Critique, la "realidad" se evaporaba y sólo quedaba el lenguaje. Por eso en un Debate sobre la

\footnotetext{
${ }^{2}$ En realidad, el llamado giro lingüístico comenzó a establecerse en los años cincuenta y en el fondo supuso el paso del análisis de las ideas al de los significados, luego de los significados a los enunciados y, finalmente, una variedad de espacios que acabaron englobándose bajo el término general de filosofía analítica. Muy pronto aparecería también la semiotización derivada de la influencia europea y de la propia tradición americana de Peirce, Dewey o W. James, arraigándose en el propio pragmatismo norteamericano. Un buen resumen de todo esto puede hallarse en la edición en castellano del libro de Richard Rorty El giro lingüístico (Rorty, 1990).

${ }^{3}$ Aunque Foucault habló magníficamente de los primeros catorce números de Tel Quel, lo cierto es que publicó un único artículo en la revista.
} 
novela ${ }^{4}$, Foucault podía decir que «Vivimos en un mundo de signos y de lenguaje», para añadir a continuación: «La realidad no existe, lo único que existe es el lenguaje».

Sin saberlo, Foucault estaba ya planteando las bases para su (para el) Constructivismo cultural en cualquier sentido lingüístico y semiótico ${ }^{5}$. De cualquier modo, en 1964, en la Universidad Saint-Louis de Bruselas, Foucault dictó un pequeño curso en dos sesiones bajo el título de Lenguaje y literatura, un curso que permaneció inédito en francés hasta 1994 y en castellano hasta 1996. En ese curso es donde se nos dice que: «No es tan seguro que Dante o Cervantes o Eurípides sean Literatura»; pero como esto parecía un exceso, Foucault se rehace enseguida para remitirnos sólo al mundo grecolatino. Y precisa: «Forman parte de nuestra literatura, no de la suya, por la magnífica razón de que la literatura griega no existe, como tampoco la literatura latina [...] Si la relación de la obra de Eurípides con nuestro lenguaje es efectivamente literatura, la relación de esa misma obra con el lenguaje griego no era ciertamente literatura» (Foucault, 1996: 63-64). ¿Por qué? Porque la literatura sólo existiría desde el siglo XIX, desde que los signos lingüísticos comienzan a referirse a sí mismos, comienzan a reflexionar sobre sí mismos y en consecuencia la propia literatura comenzaría también a socavarse a sí misma ${ }^{6}$. Foucault se está refiriendo a Flaubert (y sobre todo, por supuesto, a Mallarmé), pero esto es puro Roman Jakobson pasado por Tel Quel y es puro fracaso de la escritura pasado por los discípulos de Kojève.

Baste con algunas anotaciones al respecto: digamos así que también Paul de Man realizó su tesis doctoral sobre Mallarmé a partir de los presupuestos de la conciencia desgraciada o del fracaso de la escritura según la lectura debida a Kojève de la Fenomenología del Espíritu y en especial del célebre capítulo IV. Paul de Man publicó varios artículos sobre el tema, calcando en Mallarmé las vueltas y revueltas de ese Espíritu hegeliano interiorizado (aparte de la casi inevitable influencia de Heidegger). Posteriormente, de Man saldría de tal negatividad a través de una revisión del concepto de alegoría (versus el simbolismo organicista con que se había leído a los románticos), sin duda a través de Walter Benjamin y estableciendo así las "alegorías de la lectura" y el uso de la Retórica aplicadas a Rousseau o Proust en especial. Paul de Man consiguió que Bataille publicara en Estados Unidos y que se invitara a Derrida a Yale, con lo que la presencia de la de-construcción iba a aumentar fuertemente en América. Por su parte,

\footnotetext{
${ }^{4}$ Cfr. los comentarios al respecto de Ángel Gabilondo en el largo prefacio introductorio a la recopilación de textos de Foucault titulada De lenguaje y literatura (Gabilondo, 1996).

5 Pero fijémonos en que el "simbolismo cultural" de Cassirer no andaba lejos; aunque quizá se le haya olvidado demasiado, excepto en la reivindicación continua de Lévi-Strauss.

${ }^{6}$ Evidentemente todos estos planteamientos foucaultianos no tienen nada que ver con lo que planteé en 1974 acerca de que «La literatura no ha existido siempre». Yo no sólo desconocía, como casi todo el mundo, estos textos inéditos de Foucault, sino que mis planteamientos no tienen absolutamente nada que ver con los foucaultianos.
} 
Bataille hizo más hincapié en la transgresión erótica como sacralización y pulsión de muerte (cfr. su Historia del ojo), y en la misma estela se inscribiría Klossowski, prologando a Masoch o escribiendo La revocación del Edicto de Nantes. Blanchot respondería al ¿Qué es la literatura? de Sartre al señalar que cada obra supone ya esa misma pregunta, puesto que el ser de la literatura no existe. Y mientras el surrealismo seguía perviviendo en Queneau, el escriturismo objetivista se impuso desde RobbeGrillet o Michel Butor (y a través de Barthes), a la vez que Lacan aplicaba el psicoanálisis de la mirada (el de Los cuatro conceptos fundamentales del psicoanálisis) a la novela de Marguerite Duras El arrebato de Lol V. Stein, con un artículo que causó cierto revuelo.

Como se ve, en los herederos del Hegel de Kojève se mezclaban el surrealismo, la fenomenología y finalmente la objetividad estructuralista que enseguida iba a dar paso a la narratología de Genette, la semiótica de Greimas, la hermenéutica de Paul Ricoeur, etc. De cualquier modo, en esos finales de los setenta, la tradicional gran cultura francesa dio sus últimas muestras de validez, aunque Godard y Truffaut siguieran dejando alguna huella de su talento creativo. Paul de Man murió muy pronto y sólo Derrida y Deleuze pervivirían junto a Julia Kristeva o Hélène Cixous, mientras que Lévi Strauss siguió trabajando hasta casi los cien años. Pero aquella coyuntura no sólo fue un Réquiem francés: en los 80-90 la cultura europea (que había resurgido muy fuerte tras el horror de la II Guerra Mundial, sobre todo en Italia, Francia y Gran Bretaña) se fue diluyendo de manera implacable. Podría decirse que sólo los Beatles fueron admitidos como iconos "creadores" dentro del nuevo horizonte ideológico que estaba apareciendo, con performances, happenings, virtualidad tecnológica, etc. Y quizá por eso resulta tan llamativa la pervivencia en los casos de Heidegger y Foucault. Sólo que ya en Bruselas, en 1964, Foucault comenzaba a hablar también de la necesidad de analizar el lenguaje como "ser del lenguaje" (Heidegger de nuevo) y se nos comenzaba a hablar de la "transgresión" y del "cuerpo del lenguaje", que en realidad, como señala Ángel Gabilondo, remitía al propio cuerpo de Foucault. Aunque, sin duda, convendría matizar como hemos hecho otras veces, que la imagen del "cuerpo" proviene en Foucault de la Fenomenología husserliana con su despliegue posterior en Merleau-Ponty, etc.

3. Pues el delirio (o la transgresión) del lenguaje y la imagen del cuerpo, que afloraban con claridad en Historia de la locura, se iban a hacer más patentes en Vigilar y castigar (1975), quizá el libro que más ha perdurado de Foucault con sus famosas tecnologías del cuerpo y sociedades disciplinarias redundando en el encierro, el panóptico y el orden. Algo que ya había aparecido en 1971 en el no menos famoso El orden del discurso, donde se resaltaba la violencia de la relación entre Poder y Saber. Esta noción 
del poder nietzscheano (algo que al final se volverá realmente abstruso en Foucault), como las imágenes del ser del lenguaje o de las tecnologías del cuerpo, nos remiten de hecho (en El orden del discurso) a otra imagen clave: «Nuestra civilización se ha olvidado de algo esencial (es una variante del olvido del ser de Heidegger) y eso nos está llevando a la hecatombe». Lo señala con su justeza habitual el profesor Moreno Pestaña (siguiendo a Vattimo), sólo que Moreno Pestaña añade más: que la fascinación de Foucault por la obra de Heidegger resulta indudable ya desde sus primeros trabajos. Yo mismo resalté hace algún tiempo algunos ejemplos clamorosos (Rodríguez, 2002): en Las palabras y las cosas lo que se nos cuenta es el Historial del lenguaje del ser (o del ser del lenguaje) a través de sus desvelamientos en diversas Epistemes o epocalidades énticas que están calcadas de las epocalidades de Heidegger, etc. ${ }^{7}$

De cualquier forma, desde el ser del lenguaje y desde las técnicas sobre el cuerpo y la relación poder/saber pasaríamos a La voluntad de saber (o sea, al comienzo de la trilogía foucaultiana sobre la Historia de la sexualidad), la verdadera clave del Constructivismo culturalista. La pregunta nuclear de La voluntad de saber (el primer volumen, de 1976) era la decisiva: ¿Por qué yo soy socialmente sexo? Y de ahí el rastreo foucaultiano sobre el cómo de que la sociedad burguesa nos hubiera clasificado a través del sexo: Primero la clasificación entre hombres y mujeres; a continuación la norma heterosexual y la alianza "socio-matrimonial"; y a partir de ahí los dispositivos de exclusión, de marginación (como en el anterior caso de los "locos"), es decir, las normas que implicaban lo considerado como perverso o como obseso o como anormal en suma, incluidas las normas sobre la homosexualidad (Foucault, decimos, anduvo siempre "preocupado" por eso, incluso con dos intentos juveniles de suicidio). Ahora bien: lo que no se esperaba Foucault (ni nadie) era el éxito clamoroso que estos libros iban a tener en Estados Unidos, como también indicábamos. Claro que la coyuntura resultó decisiva: la década de los sesenta-setenta en Norteamérica estuvo marcada por la lucha contra la guerra de Vietnam, por la "contra-cultura", por los derechos de las mujeres y del feminismo y por supuesto por los derechos civiles de los negros (luego afroamericanos), etc. De ahí arrancó todo. Tanto que hasta en la filosofía analítica empezaron a aparecer los primeros brotes foucaultianos sobre marcos socio-históricos del lenguaje, algo inconcebible antes. Pero sobre todo los derechos de las mujeres y los negros fueron la clave. Puesto que la pregunta de Foucault, ¿por qué soy socialmente sexo?, se iba a trasladar inmediatamente a la radical pregunta feminista de fondo: ¿por qué yo soy socialmente mujer? (o sea, una marginada o una secundaria), e igualmente a la pregunta de los de color: ¿quién se ha inventado que el color de la piel suponga marginación y muerte?

\footnotetext{
${ }^{7}$ Los ejemplos podrían multiplicarse, sin poner con ello en duda "la originalidad de Foucault".
} 
Subjetividad y subjetivación en la cultura de hoy...

4. Por supuesto estas preguntas no ponían para nada en duda el sistema capitalista, sino que se basaban precisamente en él: si tenemos la Constitución y los Derechos civiles y los Derechos humanos ¿por qué se nos excluye o se nos margina? Y la respuesta resultaba obvia: no por ninguna esencia biológica sino por una obsesiva "construcción cultural". Por supuesto que las mujeres y los negros adquirieron sus derechos y su ciudadanía gracias a sus propias luchas masivas, pero en medio de esas luchas masivas estaba también la acumulación masiva de libros, teorías, acontecimientos, happenings rockeros, hippies y multiétnicos. En suma, una lucha tremenda que iba a acabar pacificándose -en el nivel de las prácticas teóricas- a través de los susodichos Estudios culturales o de género o postcoloniales, etc. ¿Y qué mayor solicitación para construir las nuevas formas de subjetivación corporal y vital que los trabajos de Foucault? Sobre todo teniendo en cuenta que Foucault se basaba en las raíces mismas de la civilidad americana: es decir, las raíces del "yo libre" (como subjetividad que nunca se ponía en duda), y a partir de ahí la denuncia de las tecnologías sistémicas que se imponían sobre el cuerpo libre del yo libre. Era un planteamiento muy similar al de Emerson o al de Thoreau $^{8}$. Era algo que permitía incluso "semiotizar" históricamente las líneas de un determinado marco de pensamiento y de comportamientos vitales que podían ir desde los hippies a los yuppies, de forma transversal (puesto que las dislocaciones y las explotaciones de clase desaparecían en Foucault).

5. Lo curioso es que de hecho los Estudios Culturales habían comenzado en el ámbito británico, con cierta raigambre marxista, a partir de Raymond Williams y del primer Stuart Hall, que desde 1964 dirigía el Centro de Estudios Culturales en Birmingham ${ }^{9}$

\footnotetext{
${ }^{8}$ Sobre el despliegue socio-ideológico del individualismo y del pragmatismo norteamericano resulta imprescindible el libro de Louis Menand El club de los metafísicos. Una historia de las ideas en América (2002). Es un análisis exhaustivo acerca de Holmes, William James, Dewey y Peirce (el subtítulo del libro que aparece en la traducción no se hallaba en el original de 2001). Dewey y W. James se formaron ampliamente en Alemania y fueron buenos lectores de Hegel y Kant, aunque lógicamente los tradujeran al "experiencialismo" de sus parámetros empiristas. La continuidad de esta tradición americana (Thoreau, Emerson, Whitman) en los años 50-60 entre los escritores beats más relevantes, como Burroughs, Ginsberg o Kerouac, resulta transparente, y puede verse en el lúcido libro de James Campbell Loca sabiduría. Así fue la generación Beat (2001; aquí es la primera parte del título la que no aparece en el original inglés). «Where are we going, Walt Whitman?», se preguntaba Ginsberg en el poema "Un supermercado en California". Fue esa California empapada en la herencia beat la que acogería a Foucault en los años 70.

${ }^{9}$ Stuart Hall fue también director de la New Left Review. El ensayo de Hall titulado en su edición española Los hippies: una contracultura (1977) supone un magnífico ejemplo de lo que pudieron ser los Estudios culturales. Luego, tales Estudios, como el propio Hall, prefirieron seguir la vía blanda de Paul Goodman (la crítica de Goodman a On the Road, de Kerouac puede contrastarse con el ensayo citado antes), la vía del "Nuevo Periodismo" y las premoniciones tecnológicas de McLuhan. Si se le añade a esto el sexo, drogas y rock and roll, la desaparición de la política y la importancia del "viaje interior" y de las
} 
(con Hall empezó también Terry Eagleton). Pero la construcción cultural de la mujer y la construcción cultural de los negros lo cambiaron todo por su efervescencia masiva de lucha, y por sus teorizaciones básicas: no existe realidad esencial alguna. Sólo la del "yo nací libre"; el resto es sólo una pérfida sarta de construcciones culturales. En los estudios de Género (o sea, en la construcción hombre/mujer) se inscribiría enseguida el feminismo de la Diferencia (y ahí intervendrían la diferencia de Derrida y de Hélène Cixous, etc., y el "no-todo fálica" de cada mujer en Lacan); hasta que básicamente a partir de Judith Butler, se abrieran paso las "teorías Queer" (o, en términos de Foucault, la multiplicidad de los placeres y sus usos). En suma: no hay género ni normas en ningún aspecto. Ni sexualmente, ni políticamente, ni literariamente ni en filosofía o en arte: todo se puede mezclar porque todo es lenguaje arbitrario, un puzzle de símbolos y signos, una repetición/diferencia que se establece en un instante y se borra de inmediato (quizá aquí se traslucía de manera opaca la vieja tradición metafísica entre esencia y apariencia, sólo que tachando la esencia y dando todo el valor a la apariencia, a las superficies, al "todo vale").

6. Lógicamente a Foucault, que se había trasladado a Berkeley con los beats y los hippies, aquellos campos californianos, decíamos, debieron de parecerle maravillosos ${ }^{10}$. De modo que en el curso 78-79, en París, decidió dar un paso decisivo hacia la pospolítica (al igual que los heideggerianos estaban hablando ya de la era postmetafísica). De ahí surgió en pleno la noción de biopolítica, esto es, la construcción cultural de la política entendida como forma de la gobernabilidad o gobernanza de la vida colectiva y de la vida propia, la de cada uno y la de los otros. Y así surgió también lógicamente su pasión, en ese curso, por la Escuela de Chicago: por la libertad de mercado como signo de la libertad individual y como imagen de que cada uno debe ser "empresario de sí mismo" -lo señaló atinadamente el profesor Francisco Vázquez García (1987)- y asumir sus propios riesgos. La tradición ideológica norteamericana del "cada uno es su propio presidente" se había trasladado ya al lenguaje del "cálculo" de vida neoliberal. Quizá por eso Rorty llamó a Foucault "el caballero de la autonomía”. Pero el cálculo tenía más connotaciones: todo es reducible al economicismo vital de bienes y pérdidas (afectivas, sentimentales, amorosas, etc.): la economía era ya la única cara. Cada uno debía "construirse" libremente a sí mismo dentro del mercado libre y sin intervención pública o estatal. Obviamente era un aplauso de Foucault al neoliberalismo que ya empezaba a imponerse en los Estados Unidos.

\footnotetext{
“puertas sensibles de la percepción” se comprenderá fácilmente el triunfo pop de la posmodernidad en los años 80-90 hasta nuestros días.

${ }^{10}$ No sin algún problema, como señalan Moreno Pestaña (2006) y Jacques A. Miller (1995).
} 
7. Pues, en efecto, Friedman y los demás leones de la Escuela de Chicago habían olfateado bien el problema con que se encontraban los jefes yanquis de principios de los setenta (Kissinger y los banqueros) ante las luchas civiles internas y ante una guerra en Vietnam cuyos costes económicos se habían disparado y cuya impopularidad crecía de forma desmesurada. La primera guerra que iban a perder (o que habían perdido) los Estados Unidos. Aquello era intolerable. Pero, para colmo, había surgido otro grano en el propio "Patio trasero" americano: en Chile, el único país con tradición digamos democrática en Latinoamérica, estaba a punto de ganar -a través de las urnas- el gobierno del socialista Allende. Algo que, dada la coyuntura, suponía un auténtico Gambito de caballo (como titularía W. Faulkner a una de sus novelas) realmente intolerable. Precisamente por ese carácter democrático. Friedman y Kissinger se pusieron de acuerdo y los dos se entrevistaron con Pinochet. El resultado es bien conocido: no sólo el genocidio chileno (y luego las dictaduras criminales en Argentina, Uruguay y en toda Latinoamérica), sino algo más profundo: el dictador Pinochet iba a triunfar en apariencia como tal, pero sólo en la superestructura política. Por la base, infraestructuralmente, Pinochet jamás iba a pintar nada: la economía financiera se presentó allí con la cara desnuda y sin ninguna máscara. Como ocurriría enseguida con Reagan o Thatcher, la política se estaba transformando en mera gestión tecnocrática del gran capital y en contra de los trabajadores.

El experimento criminal de Chile fue sin duda la primera señal de alarma sobre la rendición de la política ante la economía. Fue un primer aviso, del que nadie pareció darse cuenta, hasta que a lo largo de la década del 2000 la dictadura del capital financiero se ha impuesto en todos los terrenos. Pero en los años ochenta y noventa, lo único que se celebraba era la desaparición del Muro de Berlín y de la propia URSS. Todos éramos libres, por fin. Hasta hoy en que no sabemos ni lo que somos.

8. Que Foucault no se enterara de cómo había comenzado el éxito de su tan amado neoliberalismo resultaba lógico. Él seguía siendo un "anarquista ilustrado" preocupado sólo por la construcción de otras formas de subjetivación para expresar el "yo soy socialmente sexo". Y de ahí que en ese curso 78-79 alabara hasta el extremo, como decíamos, a la Escuela de Chicago. Pero hubo más: la "liberalización" de todo suponía que el dólar se iba a desprender del patrón oro y que por lo tanto los USA iban a hacer con su moneda y con su libertad financiera lo que les diera la gana. Chomsky lo señaló 
bien en $1988^{11}$ en Managua, cuando el sandinismo estaba asfixiado por "la contra" -pagada por los USA- pero aún era sandinista. Chomsky decía: Estados Unidos es el país más democrático y más libre del mundo, pues cualquier debate y cualquier discusión es posible. Sólo que añadía: siempre que no se pongan en duda los presupuestos implícitos (“indisputados”) en tales debates. Obviamente los presupuestos implícitos eran los del capitalismo norteamericano. Sobre los derechos civiles y los derechos humanos se podía discutir, pero las raíces del sistema eran intocables (volveremos sobre esto).

Con lo que resulta no menos sintomático que progresivamente a los Estudios culturales y -sobre todo- a las ciencias humanas o sociológicas se les acabara llamando en la Academia norteamericana "ciencias de la gobernabilidad" o de la "gobernanza"12. "Gobernabilidad" o "gobernanza" que no tenían ya nada que ver con la política (se daba por supuesto que, tras la caída de la URSS, la política como tal ya no existía, sólo la planificación del nuevo modelo social establecido para siempre). Con una consecuencia obvia: el desvanecimiento de la política implicaba el progresivo deterioro de la democracia ciudadana.

9. Pero lo que nos importa es que Foucault permanecía impertérrito: en 1982-1983 dictó su último curso en el Collège de France, con el título bien significativo de El gobierno

\footnotetext{
${ }^{11}$ Cfr. Noam Chomsky (1988: 143-145). Para un análisis de las contradicciones de Chomsky, partiendo también de mi profundo respeto hacia él, puede verse mi ensayo "Ideología y lingüística teórica. De Saussure a Chomsky" (Rodríguez, 1999: 63-136).

${ }^{12}$ Cfr. Burchell, Gordon y Miller (1991). Sin duda, Colin Gordon ha sido el mayor legitimidor del "efecto Foucault" en la década del 2000 en el mundo angloamericano, en medio de la turbamulta de proposiciones por establecer el neoliberalismo como la racionalidad actual y el consiguiente desmantelamiento de las conquistas sociales anteriores. El "efecto Foucault" implicaría así evaluar y gestionar el riesgo, pero lo más significativo para nosotros radica en llegar a comprender cómo esa categoría foucaultiana de riesgo, se fue transformando, a través de estas múltiples variantes, en las tres categorías sociales y biomédicas hoy establecidas: high risk, medium risk y low risk (en cualquier evaluación de cualquier tipo). No es preciso señalar hasta qué punto la "prima de riesgo" nos rodea hoy familiarmente en un lenguaje nada habitual hasta hace poco. Pero resultaría curioso, cuando menos, analizar este trasvase de lenguajes desde Foucault a las ciencias de la gobernanza y de ahí a las compañías privadas de seguros, a la psiquiatría y a la criminología, a la más simple operación de apendicitis o a cualquier acontecimiento bélico o a una amenaza financiera brutal. Puesto que fue Heidegger quien planteó lo de la poesía de riesgo o el riesgo poético en sus análisis sobre Rilke, Trakl, etc. en los años 2030. Y de ahí sin duda tomó el término Foucault antes de que se produjera el neoliberal "efecto Foucault" (sólo que el alegato para asumir el propio riesgo estaba ya también inscrito en el alfabeto hippie-beat: «Haz lo tuyo / Do your own thing»). Insisto en que resultaría fascinante analizar esta serie de posibles trasvases, y ofrezco sólo un indicio primario: en la Carta sobre el humanismo Heidegger respondía a la última pregunta que le había planteado Jean Beaufret (sobre la filosofía como "aventura"), indicando que en efecto el pensar o el poetizar se convertían en un riesgo (Gefahr) si al auto-reflexionarse no estaban marcadas por un destino (destinalmente). Hölderlin, sin duda, habría superado ese riesgo, pero Trakl o Rilke se habrían quedado en el límite y ese sería su gran mérito: atreverse con el riesgo. Quizá por eso Foucault añadió lo de la seguridad, o sea, la aludida relación actual entre evaluar y manejar el riesgo, algo que no sé cómo se retraduciría ahora a la escritura poética.
} 
de sí y de los otros (determinante en el mundo anglosajón para el citado "efecto Foucault"), y en 1984 aparecieron los dos últimos volúmenes de su Historia de la sexualidad, subtitulados El uso de los placeres y El cuidado de sí mismo. Suponían obviamente unos inventos (en gran medida al estilo heideggeriano, aunque con otro sentido) de la Grecia clásica, con una doble finalidad obvia: el uso (o la multiplicidad) de los placeres implicaba la anulación de la imagen del "yo-soy sexo"; mientras que el cuidado de sí mismo (una variante sin duda del "empresario de sí mismo") servía para colocarnos en el final de aquel mundo feliz inventado y en el comienzo del derrumbe de la clasicidad grecolatina. Esto es, el ideal absoluto de la propia Paideia (que, como debería saberse, en absoluto era un ideal para Heidegger) se habría disuelto por culpa de la aparición del Cristianismo. Ésta es sin duda una influencia del Hegel de Kojève, a través de las figuras del citado capítulo IV de la Fenomenología del Espíritu. Ahí el Cristianismo, en el Hegel pleno, supone (tras los estoicos y los escépticos) el momento de la conciencia desgraciada pero a la vez el paso hacia la salvación de esa misma conciencia a lo largo de los meandros del cristianismo. Pero éste se convierte para Foucault en el ámbito de lo demoledor, en el culpable de todo. Así el sacerdote (que en Hegel es "mediador" positivo en el paso de la Negatividad de sí a la Positividad de la Razón) queda anclado para Foucault en la negatividad radical. Con los dos ejes básicos eclesiásticos: la Pastoral (con la cual los "pastores del ser" habrían convertido a sus seguidores en gregario rebaño de ovejas) y la Confesión, en la que el "cuidado de sî" (en su trasfondo heideggeriano: el cuidado del propio ser del lenguaje) se traspasaba al cuidado dependiente del Otro, del sacerdote convertido en "señor" de cualquier yo y cualquier lenguaje ${ }^{13}$.

De todos modos eso ya no importaba, puesto que (aparte de que Foucault muriera en el año 85) el constructivismo cultural en que él se había basado, parecía imponerse por todas partes: «la realidad no existe, tan sólo existe el lenguaje», se transformó en eslogan básico de la posmodernidad y luego de las teorías Queer, y aquello parecía definitivo. Se había pasado de la construcción de las figuras culturales a la construcción linguiística de la realidad social. Se había pasado del "mundo del texto" al "mundo como texto". Y en esas andamos.

10. Curiosamente en el año 2000 fue Richard Rorty el que arremetió más seriamente contra esta influencia de Foucault en los Estados Unidos, puesto que Rorty había sido uno de los pocos filósofos pragmatistas que no habían estado muy de acuerdo con el

\footnotetext{
${ }^{13}$ Evidentemente esta "genealogía de la moral", presentando al Cristianismo como gozne, nos ofrece un planteamiento que debe leerse, a la vez, desde el último Nietzsche. Sobra decir que la imagen nietzscheana de "genealogía" permanece siempre en Foucault.
} 
auge de la Escuela de Chicago (siguiendo la línea de Paul Goodman, Jack Newfield o Theodore Roszak y de toda la aludida "crítica positiva" de la tradición americana). Y así en su libro Filosofía y futuro, Rorty hacía un diagnóstico bastante preciso de lo que él consideraba como "izquierda foucaultiana" (Rorty, 2002: 181-183). Y nos decía que en la nueva izquierda estudiantil nacida en los años setenta, tras el triunfo de Nixon, se extendía la convicción de que el país era un caso perdido: «Muchas personas comenzaron a leer a Foucault y formaron una izquierda foucaultiana que no pudo ofrecer ninguna alternativa política». Llevando su sarcasmo hasta el extremo, continuaba Rorty: «Irving Howe, el jefe de redacción de Dissent, nuestra revista izquierdista más importante, dijo de la izquierda foucaultiana: esta gente no quiere hacerse cargo del gobierno sino de la facultad de Filología inglesa» ${ }^{14}$. Y en el mismo lugar concluía:

Así ocurrió en efecto y una parte importante de la universidad se convirtió en zona del activismo político. Sin embargo este activismo se ocupó más de las cuestiones racistas y de la diferencia de los sexos que de cuestiones de las clases sociales. Desde la década de 1960 esta izquierda hizo mucho por los derechos de los negros, de las mujeres y de los homosexuales. Pero nunca intentó desarrollar una posición política mayoritaria. Siempre descuidó las cuestiones económicas mientras no estaban relacionadas con problemas racistas y de la diferencia de los sexos.

Por supuesto, Rorty resumía en estos párrafos su libro anterior, Achieving our Country, donde planteaba la necesidad de re-crear una izquierda socialdemócrata en Estados Unidos al estilo del New Deal, pues le preocupaba, como decimos, la aparición sin más del neoliberalismo. Por eso concluyó el ataque a la llamada izquierda foucaultiana de una manera drástica: «El tema de la creciente inseguridad económica (que todo el mundo percibe en Estados Unidos menos el cuarto superior más rico de la población) lo dejaron en manos de los demagogos de la derecha...».

Este ataque radical al constructivismo culturalista por su inoperancia política real suponía en realidad, por parte de Rorty, un intento de recuperación de una izquierda intelectual "patriótica" y que ayudara a consolidar el país. Evidentemente la imposible reconstrucción de un New Deal se vino abajo con la caída de las "Torres Gemelas" en 2001 y con la nueva actitud bélica de los Bush. La perspectiva neoliberal inundaba pues Estados Unidos, igual que toda Europa, pero resulta significativa la posición de Rorty por intentar detener lo que se venía encima. Y no es que Rorty no fuera un liberal pragmatista y un constructivista cultural a su modo. Por supuesto que lo fue (y siempre anduvo moviéndose dentro de la triada básica del empirismo: mente/lenguaje/mundo, y de las "creencias útiles" del pragmatismo). Pero en su última etapa, cuando abandonó el

\footnotetext{
${ }^{14}$ Acaso no haga falta recordar que hoy el término Filología se considera una antigualla en los Estados Unidos, donde prácticamente ha desaparecido en los Estudios Culturales.
} 
terreno de la filosofía analítica estricta (que sólo funcionaba en un espacio reducido) para dedicarse a la Teoría literaria, a Rorty el constructivismo foucaultiano le pareció también demasiado poco eficaz. Por eso elaboró su propia teoría lingüístico-cultural basándose en su vieja relación con Donald Davidson (el gran discípulo "hereje" de Quine), pero sobre todo en Dewey y Hegel. De cualquier modo para Rorty siempre estuvo claro que la sociedad era un proceso de comunicación intersubjetiva (a pesar de sus diferencias con Habermas). Algo que se podía restablecer a partir de dos ámbitos: en sentido analítico, a través de símbolos y signos; y en sentido conversacional como la consolidación de un grupo o un «proceso conversacional de voluntades colectivas». Como en el fondo todo esto era pura Retórica (retórica más seria en Rorty, retórica mucho más diluida en los conservadores supuestamente progresistas, como Ernesto Laclau o Chantal Mouffe), la única solución era asumir esa Retórica hasta el final: en el "proceso conversacional" no se negaba que existiesen los conflictos y los antagonismos entre lo particular y lo universal, se planteaba sólo que esos conflictos y antagonismos (fueran subjetivos o colectivos) siempre se resolverían a través de la retórica y la semántica aplicables al propio grupo interdependiente, etc.

Y así Rorty (y sobre todo su seguidor Laclau) deformaron al extremo la noción de Gramsci de Hegemonía: la hegemonía supondría ahora para ellos el dominio del sistema dentro de los Estados Unidos y el dominio de una parcialidad (los propios Estados Unidos) en el sistema universal, apoyándose sobre todo, según Rorty, en las democracias noratlánticas europeas.

11. Sé de sobra que este rodeo no sirve más que como contraste frente al indiferentismo aparente de Foucault en los años ochenta y para resaltar esta reacción (digamos keynesiana) de Rorty contra la presencia abrumadora de Foucault en los USA. Pero en el fondo de los fondos lo que permanecía latiendo en Foucault era la vieja relación metafísica sujeto/sistema (como habíamos indicado al principio), algo que procuraba ignorarse al ser adaptado en los Estados Unidos. Hasta que por fin Foucault descubrió todas sus cartas, que evidentemente servían para todo. Y así en los momentos últimos de su vida Foucault declaraba claramente sus planteamientos: «Yo no he querido decir que estamos siempre atrapados, sino al contrario, que somos siempre libres» (Foucault, 2004-2008: IV, 740).

\section{II. ¿Poesía lírica y no-lírica? Un camino por re-trazar}

1. Llegamos con ello al final: con Foucault hemos pasado de las sociedades disciplinarias a las sociedades de control; hemos pasado por la relación del cuerpo y la 
resistencia; por la biopolítica; por las subjetivaciones (o las formaciones discursivas) frente a la sujeción dentro de la siempre latente relación sujeto/sistema; y hemos llegado en fin a la gobernabilidad del cuidado de sí y de los otros, lo que implicaría no un esencialismo del sujeto social sino un esencialismo del yo libre.

Más claro el agua: naceríamos -esencialmente- libres e iguales y luego nos diferenciarían los dispositivos sociales que (psicológica y sociológicamente) nos calificarían a través del yo-soy-sexo. Hoy, afortunadamente, y gracias al capitalismo neoliberal, nos habríamos posibilitado una libertad auténticamente real, asumiendo el propio riesgo y estableciendo normas ético-políticas de seguridad desde lo íntimo a lo público $^{15}$.

2. El único problema: ¿de dónde se saca Foucault esta historia? Evidentemente se trata de un calco de la evolución del Espíritu Humano condensado en el lenguaje y de una evolución en la que sus diversos estratos más que superarse se van acumulando hasta encontrar una salida final. Pero lo cierto es que Foucault nunca nos explica por qué se pasa de una formación social a otra, salvo acaso por los cambios del lenguaje (desde la exterioridad referencial a la auto-referencialidad de los signos literarios, por ejemplo), o por la evolución del poder (como absoluto) hacia la gobernabilidad (como control). $\mathrm{O}$ cualquier otra variante por el estilo. Lastimosamente esto es lo mismo que no decir nada respecto a una perspectiva histórica real y objetiva ${ }^{16}$. Pero a Foucault parecía importarle sólo el decir yo soy yo. Y por supuesto reconocemos sus aportaciones filosóficas e históricas como muy importantes.

Sólo que con un trasfondo completamente arbitrario y -repito- colgado de las nubes.

No sin argucias inteligentes: por ejemplo, cuando trata de sustituir la infraestructura económica marxista por la infraestructura vital del cuerpo, establece a la vez el muy hábil axioma de que el poder viene desde abajo. Es una máscara, pero a él le vale perfectamente y además nos indica cosas válidas. A la vez, cuando señala que las superestructuras del poder son en realidad disciplinas o tecnologías sobre el yo nos está indicando que se trata de sujeciones del yo. A las que el yo puede, pues, enfrentarse a

\footnotetext{
${ }^{15}$ Ciertamente, en la estructura del "efecto Foucault" parece que lo íntimo se expresa en lo exterior y que lo íntimo es reconocido como formas de subjetivación y de construcción de lo real: por eso triunfa. Sólo que la realidad social ya está construida y además nos resulta asfixiante. Claro que precisamente eso motiva a la actuación sobre la visión establecida de lo real, etc. Pero es la demanda de que se haga caso a la propia intimidad (o la necesidad de exteriorizarla como subjetivación) lo que de hecho importa. Lo cual evidentemente es básico, pero engañoso si uno/una se considera un yo naturalmente libre en vez de intentar romper con el inconsciente dominante que nos configura.

${ }^{16}$ Dejando ahora al margen el imprevisible "efecto Foucault" y las corrosivas consecuencias de la "prima de riesgo", etc.
} 
Subjetividad y subjetivación en la cultura de hoy...

través de resistencias del afuera o de subjetivaciones creadas libremente, puesto que lo único esencial es el yo libre.

3. Esta Arcadia subjetiva (libre) y colectiva (libre) no implica sólo una apología -que en Foucault es obvia- del neoliberalismo capitalista, sino que implica un bloqueo fáctico ante cualquier idea de subjetivación o de resistencia que no parta del yo libre; es decir, un bloqueo fáctico de cualquier intervención contra el límite de lo que llamábamos los presupuestos implícitos del capitalismo. O de otro modo, cualquier intervención contra el supuesto de que nacemos libres, "naturalmente" libres, de acuerdo con la imagen de la Naturaleza humana "natural" (y en ese innatismo de lo libre están enlazados tanto Chomsky como Foucault, y por supuesto Rorty o los Estudios culturales).

4. Y aquí viene nuestro problema: cuando hoy el neoliberalismo del capital descarnado ha provocado un terremoto sistémico global, y especialmente en la propia Unión Europea, los planteamientos libres de Foucault o los planteamientos retóricos de Rorty o de Laclau y de Chantal Mouffe (más cercana a Hanna Arendt) se han quedado evidentemente escuálidos, como un esqueleto lingüístico/retórico al margen de la realidad social efectiva ${ }^{17}$. Por eso en este arrasado campo de batalla actual parecen pervivir más bien (en el nivel ideológico) nombres que también venían de atrás, como en el caso de Badiou o Rancière, que se han apoyado siempre -y en especial- en otra noción clave heideggeriana: nada menos que la noción de Das Ereignis, el acontecimiento o acaecimiento propio, lo único capaz de transformarlo todo ${ }^{18}$. En una palabra: la violencia brutal del capitalismo descarnado, tanto a nivel colectivo como subjetivo, ha arrasado de tal modo que ha llevado al límite su propia relación con la democracia participativa. Y por consiguiente el riesgo vital ha diluido las posibilidades

\footnotetext{
${ }^{17}$ A pesar de que Laclau y su retórica (que sin duda es una herencia deformada de Derrida y Paul de Man) pretenda en Buffalo apoyarse a la vez en la tabla de un lenguaje psicoanalítico lacaniano "más allá del Edipo" que -por diversos motivos- hacía aguas en el año 2000, aunque Žižek intentara hacer una nueva lectura lacaniana del marxismo y J. A. Miller intentara dar seguridad a esa frágil tabla psicoanalítica.

${ }^{18}$ El profesor Arturo Casas, en su muy riguroso ensayo "La poesía no lírica: enunciación y discursividad poéticas en el nuevo espacio público" (2011), propone tres ejes realmente sugerentes para una discursividad poética emancipatoria: la subjetivación, el acontecimiento y la poesía para lo público (o para lo político). El nuevo tipo de subjetivación no tendría nada que ver con la tradicional concepción de "poesía lírica" que se ha mantenido hasta hoy (Casas cita al respecto las nueve caracterizaciones establecidas por W. Wolf); por el contrario la subjetivación supondría una reasignación de la dialéctica entre lugar y cuerpo y una capacidad de enunciación no identificable previamente. La cuestión se concreta enseguida, pues A. Casas se basa en Rancière (en sus libros: El desacuerdo. Política y Filosofía y El espectador emancipado sobre todo) para una recuperación de la política. El acontecimiento y la poesía para lo político le sirven no sólo para analizar a Badiou, Žižek o Laclau (y al propio Foucault) sino para romper con la imagen del "intelectual comprometido", algo ya archivado (según el mismo Rancière) por su "dirigismo" y su insoportable "superioridad moral" -por decirlo suavemente- en cualquier perspectiva teórica.
} 
de autocontrol (o de seguridad respecto al autocontrol y a la relación con los otros). Todo ese apacible lago de los cisnes inventado por Foucault y por los Estudios culturales se ha desquiciado ante el tsunami de la realidad efectivamente existente. Todas las normas se han roto, incluso las normas sin norma.

Aunque por supuesto no todo: el eje del "yo soy libre" (o el nacemos libres e iguales) sigue permaneciendo intacto en el inconsciente del fondo de cualquier escenario, y en especial en el fondo del escenario literario o poético.

Y aquí vendría el último matiz: a) si lo que suele llamarse poesía lírica (que nació efectivamente con las primeras literaturas burguesas, con la aparición del sujeto libre del capitalismo entre los siglos XIV-XVI ${ }^{19}$ ) se desbordó en el yo romántico y se desmenuzó en las vanguardias (como poesía íntima-pura o como poesía del compromiso político); y b) si la poesía no-lírica (la de la plaza o la de lo público), que también nació entre el siglo XIV y el XVI, algo pues que pretendería hoy ser no hermético sino, al contrario, plantearse como resistencia y como intervención (en la construcción de otra visión de lo real o de nuevas formas de subjetivación); si todo eso -digo- resulta que flota en un charco porque su funcionamiento tenía una trampa, entonces ¿cuál sería esa trampa?

5. Lo hemos venido indicando a través de todas las líneas: la trampa se inscribe en la creencia en el "yo nacido libre", en que esa es $m i$ verdadera subjetividad ("lírica") o $m i$ verdadera objetividad ("no-lírica", en relación dialéctica con lo lírico). A partir de esa trampa originaria, todo lo demás se deduce claramente: todo lo demás serían subjetivaciones impuestas o subjetivaciones que yo crearía -o bien soportándolas o bien resistiéndome y estableciendo un nuevo espacio real.

Obviamente es aquí donde se insertan tanto la influencia de Foucault como la de los Estudios culturales. Dentro de un círculo vicioso increíble: partir del yo libre para llegar al yo libre. La trampa es viscosa como la piel de una serpiente. O mucho peor aún, porque ni siquiera la notamos. De modo que habría que empezar a cambiar de circuito. Pero me limitaré a plantear tres cuestiones que considero básicas para un nuevo terreno de discusión:

$1^{\circ}$ ) ¿Qué ocurre con los que, en la estela de Spinoza, Marx o Freud no creen (o no creemos) en el hecho de que nazcamos libres e iguales?

Si ya Spinoza recibió ataques furibundos por burlarse del "libre arbitrio otorgado" en el que aún creían los cartesianos, imaginemos lo que puede ocurrir hoy, cuando en

\footnotetext{
${ }^{19}$ Cfr. Rodríguez (1990).
} 
vez del "libre arbitrio" otorgado por la divinidad se cree en la libertad otorgada por la naturaleza. Pero hay que ser coherentes: ya Marx señalaba (en la Introducción de 1857, que él no publicó nunca) que esa Naturaleza humana derivada de la Naturaleza natural era sólo un invento de "los profetas" burgueses del siglo XVIII, puesto que en realidad éramos producto de la Historia. Conviene especificar, pues, a partir de ahí, que la especie humana no es ni deja de ser libre: es sexuada, parlante y mortal (por utilizar términos lacanianos). Los seres humanos en absoluto somos producto de la naturaleza (dejando a un lado, obviamente, las cuestiones biológicas) sino que al ser productos/efectos históricos somos por tanto transformables. No en el sentido de meras tecnologías de subjetividad sino transformando la historia real que nos produce.

Ahora bien: el "nacemos capitalistas" no es un hecho histórico aislado. Exactamente igual, puede decirse que en el mundo grecolatino se nacía "esclavista" (dentro de la matriz ideológica amo/esclavo); o, lo mismo, que en el mundo feudal se nacía "siervo" (del Señor de los cielos o de los señores de la tierra, reflejos de aquél, dentro de la matriz ideológica Señor/siervo) ${ }^{20}$. Por supuesto que el "nacemos capitalistas" actual arrastra una serie de contradicciones infinitas en el interior de la matriz ideológica Sujeto (con mayúsculas)/sujeto (con minúsculas). Con el inconsciente ideológico se puede romper hasta cierto punto y hasta límites muy amplios; el problema surge en la conexión entre inconsciente ideológico e inconsciente pulsional, que están siempre fusionados; pero ¿cómo es esa fusión? De cualquier modo las manifestaciones de las "neurosis normales" (digámoslo así) siempre se expresan a través del lenguaje ideológico realmente existente (que es el único que las configura), pero con ese lenguaje de los desequilibrios psíquicos "normales", insisto, resulta dificilísimo el pacto. Y, por consiguiente, surgen muchos obstáculos para romper con el propio inconsciente en bloque. Así del "nacemos naturalmente libres" parece que no se libra nadie: ni los marxistas ni los foucaultianos ni los empiristas ni los semióticos o retóricos, ni sus mezclas. Y mucho menos en las relaciones cotidianas: todo el mundo cree en la libertad, pero sólo dentro del inconsciente de los parámetros capitalistas, que se han convertido en nuestra "vida natural", como venimos indicando desde el principio.

$2^{\circ}$ ) En consecuencia: si vamos del yo libre al yo libre (o al nosotros libres partiendo del yo naturalmente libre) sólo se trataría de reformar las instituciones dañadas o el propio sistema dañado en algo. ¿Por qué o por quién? No se sabe, porque todo sigue colgado en las nubes.

\footnotetext{
${ }^{20}$ Por supuesto que la configuración de la individualidad, de la escritura y de su función en las relaciones sociales es algo completamente distinto en el esclavismo, en la servidumbre feudal y en el capitalismo. Cuando Aristóteles o Virgilio pasan al mundo feudal o cuando Santo Tomás o la escritura medieval pasan a nuestro mundo, es cuando se establece la Tradición literaria como expresión del Espíritu Humano desde Homero hasta hoy. Eso es lo que está implícito en mi planteamiento de que la literatura (tal como la concebimos hoy) no ha existido siempre.
} 
Y $3^{\circ}$ ) La cuestión de la poesía lírica y no lírica: puesto que no creemos en esa fantasmagórica "naturaleza humana libre" y puesto que partimos del hecho de que "nacemos capitalistas" (de acuerdo con los presupuestos capitalistas de la libertad), en todo caso se trataría de objetivar al yo y de intentar configurarlo de otra manera, rompiendo -decimos- con nuestro inconsciente ideológico dominante. Presentar las cosas, en fin, desde el planteamiento de que la libertad no se tiene "naturalmente" sino que la libertad (sin explotación) se conquista.

Y a partir de aquí se abriría un camino que habría que re-trazar ${ }^{21}$ desde una perspectiva emancipatoria.

\section{Referencias bibliográficas}

BLESA, T. (1998): Logofagias. Los trazos del silencio. Zaragoza: Anexos de Tropelías.

BORGES, J. L. (1961): Antología personal. Buenos Aires, Sur.

BURCHELL, G. - GORDON, C. - MILLER, P. eds. (1991): The Foucault Effect: Studies in Governmentality. Chicago, The University of Chicago Press.

CAMPBELL, J. (2001): Loca sabiduría. Así fue la generación Beat. Barcelona, Alba.

CASAS, A. (2011): "La poesía no lírica: enunciación y discursividad poéticas en el nuevo espacio público", en D. SÁNCHEZ-MESA et al. eds., Actas del I Congreso Internacional de la Asociación Española de Teoría de la Literatura. Granada, 2628 de enero de 2011 , en prensa.

CHOMSKY, N. (1988): Sobre el poder y la ideología. Conferencias de Managua 2. Madrid, Visor.

FOUCAULT, M. (1966): El nacimiento de la clínica. México, Siglo XXI. (1983): El orden del discurso. Barcelona, Tusquets, $2^{\text {a }}$ ed. (1987): Historia de la sexualidad. México, Siglo XXI, $2^{\text {a }}$ ed., 3 vols. (1996): De lenguaje y literatura. Barcelona: Paidós e I. C. E. de la Universidad Autónoma de Barcelona.

\footnotetext{
${ }^{21}$ Arturo Casas, en el ensayo citado, presenta algunas huellas a seguir: Las cenizas de Gramsci, de Pasolini; un poema "acontecimental" de Lápidas, de Gamoneda; o el libro de Túa Blesa Logofagias. Los trazos del silencio (1998). Por mi parte propondría los Diálogos de fugitivos o el Diario de trabajo de Brecht, como ejemplos básicos del intento de alcanzar la distancia respecto a uno mismo y respecto al sistema establecido; o en otro sentido, la Antología personal de Borges (1961), en cuyo prólogo Borges pulveriza la categoría de expresión directa del yo, «a la que debemos la peor literatura de nuestro tiempo». Confieso que este ataque a la «expresión directa» del yo no lo he visto en ninguna parte (sí alguna otra manifestación indirecta, como la ficcionalidad del yo, el correlato objetivo, etc.). Sé de sobra que Borges alude sólo al "trabajo objetivo" del escritor, o a lo que Blas de Otero llamaba el «vivir de un verso por sí mismo», pero somos lectores tan "prejuiciosos" que a veces no buscamos las cosas en donde $s i ́$ se encuentran. Por supuesto que otros múltiples ejemplos de textos y espacios podrían añadirse, pero esto implicaría ya una cartografía nueva. Por ejemplo, la olvidada disputa de Gramsci con Croce sobre si el ebbe (el tuvo o tenía) del Canto X del Infierno del Dante es también algo poético (postura de Gramsci) o si bien no es sino mera estructura (postura de Croce). En el fondo: ¿existe o no una lógica poética al margen de la supuesta "expresividad lírica directa"?
} 
(2004-2008): Dits et écrits 1954-1988. París, Gallimard, 4 vols.

GABILONDO, Á. (1996): "Introducción", en M. FOUCAULT, De lenguaje y

literatura. Barcelona, Paidós e I. C. E. de la Universidad Autónoma de Barcelona, pp. 9-48.

HALL, S. (1977): Los hippies: una contracultura. Barcelona, Anagrama.

MENAND, L. (2002): El club de los metafísicos. Una historia de las ideas en América. Barcelona, Destino.

MILLER, J. A. (1995): La pasión de Michel Foucault. Santiago de Chile, Andrés Bello. MORENO PESTAÑA, J. L. (2006): Convirtiéndose en Foucault. Sociogénesis de un filósofo. Barcelona, Montesinos.

- (2010): Foucault, la gauche et la politique. París, Textuel.

RODRÍGUEZ, J. C. (1990): Teoría e historia de la producción ideológica. Las primeras literaturas burguesas (siglo XVI). Madrid, Akal, $2^{\mathrm{a}}$ ed.

- (1999): La norma literaria. Granada, Diputación Provincial de Granada.

- (2002): De qué hablamos cuando hablamos de literatura. Granada, Comares. (2011): Para una lectura de Heidegger. Granada, Universidad de Granada.

RORTY, R. (1990): El giro lingüístico. Reflexiones metafilosóficas de la filosofía lingüística. Barcelona, Paidós.

- (2002): Filosofía y futuro. Barcelona, Gedisa.

VÁZQUEZ GARCÍA, F. (1987): Foucault y los historiadores. Cádiz, Universidad de Cádiz. 